\title{
Energy Storage for Lunar Surface Exploration
}

\author{
Monica C. Guzik, ${ }^{1}$ Ryan P. Gilligan, ${ }^{2}$ Phillip J. Smith, ${ }^{3}$ and Ian J. Jakupca ${ }^{4}$ \\ NASA John H. Glenn Research Center, Cleveland, OH, 44011, United States
}

This paper presents the updated results of a previous NASA study funded under the Advanced Exploration Systems (AES) Modular Power Systems (AMPS) project. This work focuses on generating high-level sys tem sizing relationships for two lunar surface locations that serve as bounding conditions for most other locations. Four critical parameters are considered to provide sizing data: specific energy, energy density, specific power, and power density. Given the energy storage requirements or customer power demand for a lunar mission location, the data presentedin this paper provides a method to determine the critical parameter values of a Regenerative Fuel Cell (RFC) system in order to perform high-level mission architecture trades.

\section{Nomenclature}

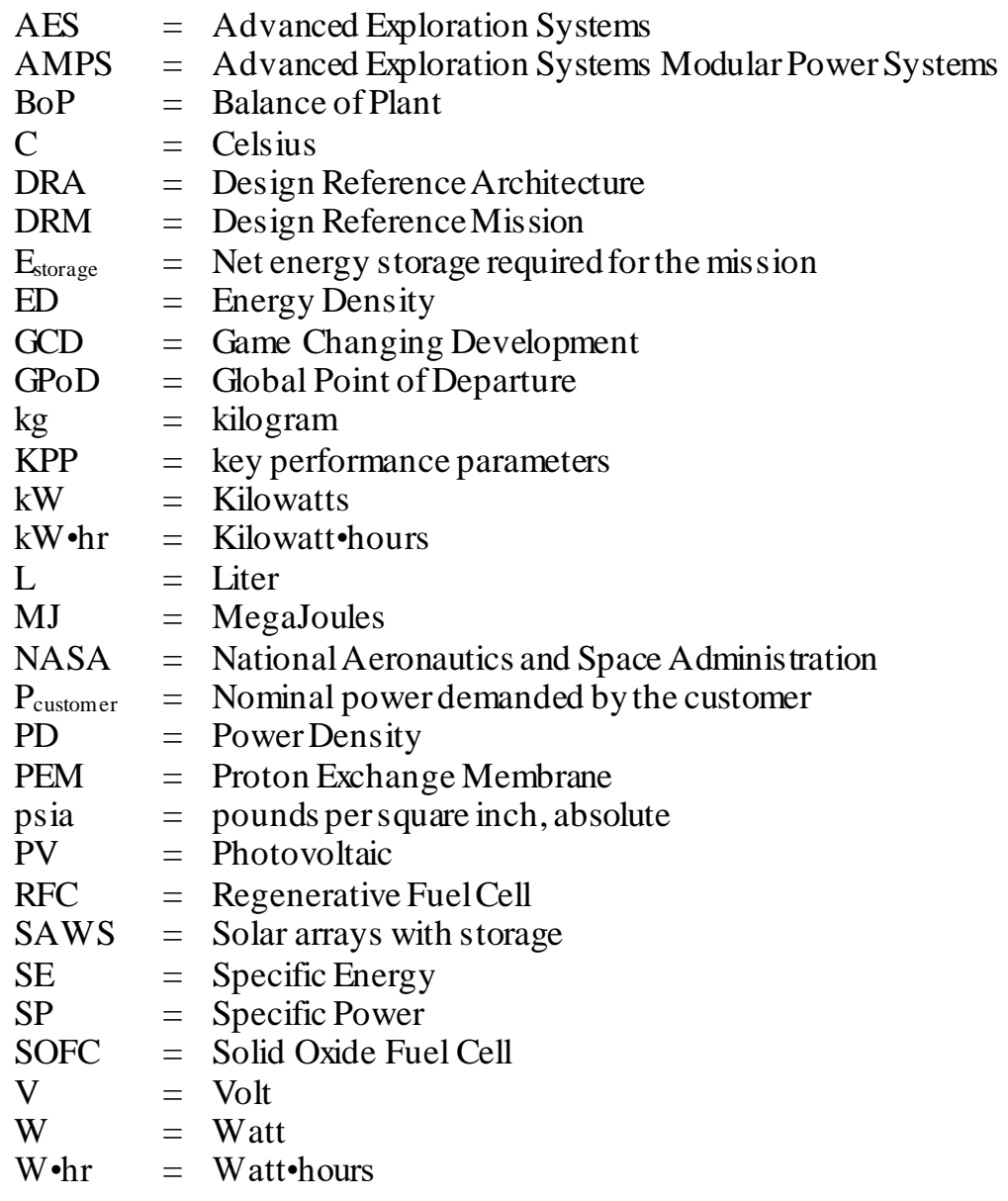

\footnotetext{
${ }^{1}$ Gas and Fluid Systems, Fluid and Cryogenic Systems Branch

${ }^{2}$ Gas and Fluid Systems, Fluid and Cryogenic Systems Branch

${ }^{3}$ Direct Energy Conversion, Photovoltaic and Electrochemical Systems Branch

${ }^{4}$ Direct Energy Conversion, Photovoltaic and Electrochemical Systems Branch
} 


\section{Introduction}

The National Aeronautics and Space Adminis tration (NASA) continues to develop technologies to satisfy the persistent need for consistent and reliable power systems that enable large-scale Lunar surface exploration, both manned and robotic. Photovoltaic (PV) solar array power systems are a popular energy source for lunar mis sions due to the high technical maturity availability of sunlight. When sunlight is not available as a power source, an altemate method of providing power must be used. The traditional power architecture solution sizes the solar array to both power the customer load and charge an energy storage system while sunlight is available. When sunlight is unavailable, the energy storage system discharges to support the customer loads. In the past, batteries have met the energy storage requirements over short charge/discharge durations with the lowest overall mas s and fewest system complications compared to other technologies. Progressing surface exploration to include manned mis sions increases the power demand by at least an order of magnitude. In addition, the leng thy eclipse durations inherent in many lunar surface exploration locations result in longer discharge periods and correspondingly higher energy storage requirements. For such mis sions, the battery mas s quickly becomes prohibitively large, necessitating an alternative energy storage method. One such alternative is the Regenerative FuelCell (RFC).

A Proton Exchange Membrane (PEM)-based RFC systemintegrates a fuel cell, an electrolyzer, and a multi-fluid reactant storage systeminto an energy storage device. The energy capacity of the RFC is determined by the amount of available hydrogen and oxygen storage. Typically, hydrogen and oxygen are stored as gases at elevated pressure, due to the advantage of decreased system volume and simplified thermal requirements. The need to reduceor eliminate the parasitic power penalty for pressurizing the reactant gases drives electrolysis to operate at high pressures, thereby eliminating the need for compressors in the system. However, the increased line and component masses that are required to contain the elevated pressures must also be considered. Previous system trades suggest that the optimum gas eous storage pressure is in the range of 1000 to $1800 \mathrm{psia}$, but may vary based on the mission requirements [1].

The RFC dis charges power through a fuel cell that converts the stored chemicalenergy of oxy gen and hydrogen into direct-current electricity, heat, and water. This product water is accumulated until it is later consumed in the charging portion of the cycle. Fuel cells are, inherently, a current-producing device with the resulting electrical potential (voltage) indicating the reaction efficiency. Increasing the system pres sure and temperature increase the reaction efficiency by increasing the molecular concentration and reaction kinetics. For PEM fuel cells, the standard operational regimes are 40 to 65 psia and 20 to $80^{\circ} \mathrm{C}$. A general operation cycle for a PEM-based RFC system is shown in Figure 1.

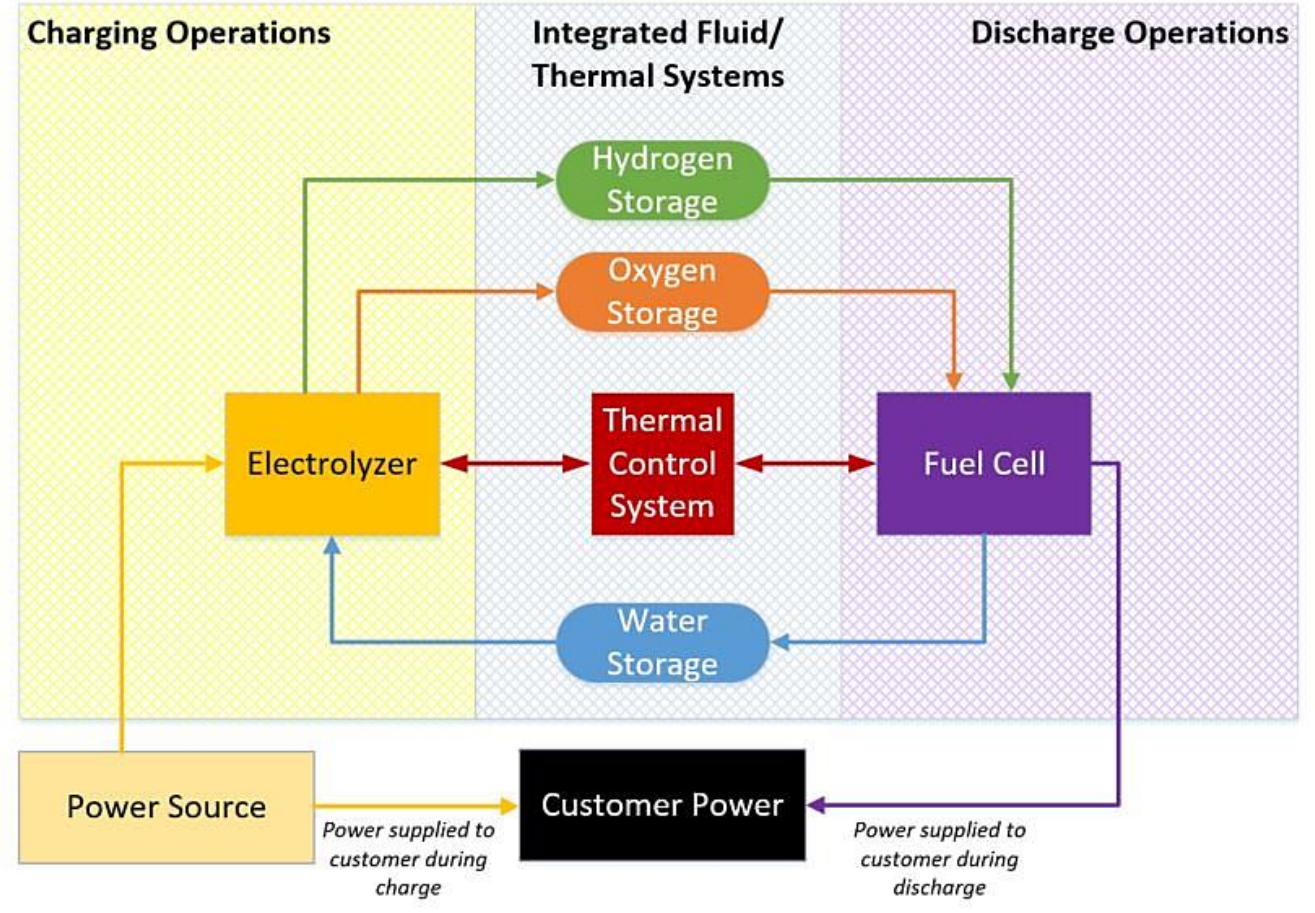

Figure 1. Simplifiedschematic depicting the charge/discharge operations for a PEM-based RFC energy storage system 
Unlike RFC systems, batteries incorporate energy conversion (power) and energy capacity (storage) into one package that encompasses both the energy storage mas s and the power production mas s. An RFC dis sociates the two masses, thereby enabling independent sizing of each. Because an RFC stores chemical energy as gases, it is able to store energy in large quantities with a relatively low mass penalty. This advantage becomes more pronounced as energy storage levels increase. NASA continues to evaluate RFC sys tems for lunar surface exploration as the subsystems and individual technology elements mature. Current studies corroborate the findings of previous studies to show that the solar-based lunar surface power architecture requires RFCenergy storage as an enabling technology for human exploration missions [2-6].

This paper presents the updated results of a recent NASA study funded under the Advanced Exploration Systems (AES) Modular Power Systems (AMPS) project using an analysis method previously developed under the AMPS project $[1,7]$. Multiple studies have been performed in the past two decades to evaluate and optimize surface power systems for lunar exploration [8-13]. This AMPS study evaluates multiple surface locations on the Moon, with the goal of establishing a common approach towards technology development and system design for surface power systems that use RFC energy storage methods. Since individual elements of an RFC system can be scale d to meet particular mis sion requirements, one RFC design may not be applicable to all surface locations. However, enough commonality exists to suggest a single preliminary development approach to answer the technology development needs for RFC systems. For this study, Proton Exchange Membrane (PEM) fuel cell and electrolysis stacks were selected due to a relatively high technical readiness and an ability to operate over a variety of pressures and flow conditions, as determined in recent NASA studies [1]. This paper focuses on the definition of preliminary RFCenergy storage system sizing relationships to help in high-level studies evaluating energy storage solutions for lunar applications.

\section{Regenerative Fuel Cell Modeling Tool Development Overview}

NASA has investigated RFC energy storage options for lunar mis sions since the late 1960s [14]. A string of Design Reference Architectures (DRA) and Design Reference Missions (DRM) supplied Key Performance Parameters (KPP) as development targets. The latest assessment of potentialmission KPP values was published in December 2017 [15]. In parallel, the AMPS program and the NASA Game Changing Development (GCD) office collaborated to study the latest incarnation of RFC energy storage technologies and evaluate the feasibility for use in lunar or Martian missions. Using identical analysis tools of the same RFC technologies, the AMPS teamfocused on lunar applications while the GCD teamfocused on Martian missions powered by deployable solar arrays with storage (SAWS).

In 2017, the joint AMPS/GCD team created two regenerative fuel cell models that predict the mas s, volume, and efficiency of an integrated RFC s ystem [1,7]. These models were based on assumed steady state operating conditions, including a constant customer power load and constant power supply to the electrolyzer. One model utilized a PEM fuel cell paired with a PEM electrolyzer, while the second model included a Solid Oxide Fuel Cell (SOFC) paired with the PEM electrolyzer. Solid oxide electrolysis was eliminated from consideration due to limitations on the pres sure at which the electroly sis can be performed. A trade study was performed to assess whether a PEM or SOFC sys tem was better suited for various mis sion locations on the Moon and Mars [1]. This tool excluded any consideration of the source of the initial power (e.g. PV, nuclear, etc.) to focus solely on the energy storage element of a power architecture.

In 2018, this steady state model was modified to account for transient power supply to the electrolyzer froma solar array supply during daylight hours. Realis tic solar fluxprofiles were added to enable accurate characterization of RFC performance throughout multiple charge/discharge cycles at various surface locations. Additionally, the model now includes updated PEM fuel cell and electrolyzer performance data, expanded component level specifications options, means to estimate solar array sizing, more user input options, and improved theoretical and empirical equation correlations. The revisions broaden the range of as sessable mis sion scenarios while simultaneously increasing model automation, accuracy, and precision.

\section{Selection of Critical Parameters for RFC Sizing}

The intent of this study is to define critical parameters used in comparing multiple energy storage options, and to develop a tool to aid in RFC energy storage system sizing for a particular location. At various lunar locations, this study will allow for a rapid as sessment of RFC performance based on preliminary power requirements through the evaluation of the four-(4) critical parameters shown in Table 1. Each of these critical parameters can be considered when evaluating and quantifying the performance of an RFC energy storage system for high-level mission trades. These parameters are characterized as a function of two independent variables: nominal power demanded by the customer, $P_{\text {customer }}$, and net energy storage required for the mission, $E_{\text {storage }} . E_{\text {storage }}$ refers to the total RFC energy 
storage capacity, while $P_{\text {customer }}$ specifically refers to the power that the fuel cell must supply to meet the customer requirement. The total fuel cell output power must account for both the power supplied to the customer as well as the power required to support parasitic RFC sys temhard ware needs.

\section{Table 1. Definition of Critical Parameters for Analysis}

\begin{tabular}{|c|c|c|}
\hline Parameter & Concept & Units \\
\hline Specific Energy, SE & $\mathrm{E}_{\text {storage }} /$ Total RFC System Mass & $\frac{W \cdot h r}{\mathrm{~kg}}, \frac{\mathrm{MJ}}{\mathrm{kg}}$ \\
\hline Energy Density, $E D$ & $\mathrm{E}_{\text {storage }} /$ Total RFC System Volume & $\frac{W \cdot h r}{\mathrm{~L}}, \frac{\mathrm{MJ}}{\mathrm{L}}$ \\
\hline Specific Power, $S P$ & $\mathrm{P}_{\text {customer }} /$ Total RFC System Mass & $\frac{\mathrm{W}}{\mathrm{kg}}$ \\
\hline PowerDensity, $P D$ & $\mathrm{P}_{\text {customer }} /$ Total RFC System Volume & $\frac{\mathrm{W}}{\mathrm{L}}$ \\
\hline
\end{tabular}

In the current mass sensitive environment, the first and likely most influential critical parameter is specific energy, $S E$, defined as $E_{\text {storage }}$ divided by the total RFC systemmass and measured in units of $\mathrm{W} \cdot \mathrm{hr} / \mathrm{kg}$ or MJ $/ \mathrm{kg}$. The second parameter is energy density, $E D$, defined as $E_{\text {storage }}$ divided by the total RFC sys tem volume and meas ured in $\mathrm{W} \cdot \mathrm{hr} / \mathrm{L}$ or $\mathrm{MJ} / \mathrm{L}$. Because total energy storage is a function of mission duration and power level, specific energy and energy density are very useful metrics for long duration missions requiring the lowest possible system mass and volume, respectively. These two parameters dominate trade spaces that prioritize the total energy storagecapability of a system. For example, a traditional manned surface exploration mis sion requires the lowest possible mass to maximize both payload and habitat capability during both daylight and eclipse periods. Another example is a lunar rover that requires its power system to have the lowest possible mass and volume for its power system in order to maximize payload capacity while als o being capable of providing the required hibernation power to survive the lunar night.

Contrastingly, some mis sion applications are primarily power-centric, and put more emphasis on power delivered to the customer rather than overall energy storage. Such a mission could include a lunar rover that is required to have a low mass, low volume, rechargeable power system capable of solar-independent operations. The rover may have access to a power source during its charging cycle that does notrely on solar power, such as nuclear power, or it may have the ability to recharge over multiple solar periods with only minimal hibernation power during eclipse periods. In addition, some crewed vehicles and ascent/descent vehicles may place more emphas is on power delivery over energy storage requirements, but retain the need for recharging at some point in the mis sion cycle. Two additional critical parameters are identified to satisfy these mis sions. One such parameter is specific power, $S P$, defined as the $P_{\text {customer }}$ divided by the total RFC system mass, and measured in W/kg. The last parameter is power density, $P D$, defined as the $P_{\text {customer }}$ divided by the total RFC system volume, and measured in W/L. These two parameters are based on nominal power values that neglect any substantial variability in load profiles, which causes the reported power density numbers to be lower than what may beobserved in a system with variable power loads. Capturing the dynamic load profiles within the mis sion trade space will require additional analysis beyond the scope of this paper.

Nearly every NASA spaceflight mis sion focuses on specific energy and specific power due to the need to maximize system output while minimizing system mass. However, some applications require equal or greater emphasis on sys temvolume, due to limitations on the allowable s ystem footprint or packaging. Energy density and power density are often key parameters when considering mobile vehicle systems such as small landers and rovers, where the RFC sys temmust fit into a small, sometimes predetermined volume to allow the vehicle to accommodateother functional sys tems and payloads. Often, the volume limit provides the mostchallenging requirement for such systems due to the relatively large volume as sociated with reactant storage. While the work presented in this paper did not include packaging optimization, it should be noted that an RFC s ystem volume could be dis tributed by subsystem volume into multiple locations in order to address vehicle center-of-gravity, thermal, or other integration is sues.

\section{Analysis Inputs and Assumptions}

Due to the varying environmental conditions and operational limitations of various mis sion locations, the data presented can only be considered valid for a specific range of lunar mis sion locations. In this study, mis sion locations at the lunar equator and lunar south pole were considered. Both locations were analyzed in a previous study, with the lunar equator representing a mission with the highest energy storage requirement, and the Shackleton Crater at the lunar south pole representing a miss ion with the lowest energy storage requirements for a lunar location and the longest daylight duration [1]. Figure 2 depicts the landing sites under serious consideration by the Constellation program in 
2009 after evaluating many potential lunar landing sites [16]. Under the Global Point of Departure (GPoD) element of the Human Lunar Reference Architecture development, this list was further reduced and divided into three-(3) categories: sortie (7-day) missions, extended stay ( $\leq 28$ days) mis sions, and long duration (70-day) missions [17]. There are 13 missions included, with five-(5) sortie mis sions, seven-(7) extended stay mis sions, and one long duration mis sion. Ref. 18 discusses the selection criteria and merits of the selected locations, as summarized in Table 2. This table illus trates that the bulk of the landing locations are in close proximity to either polar or the lunar equator.

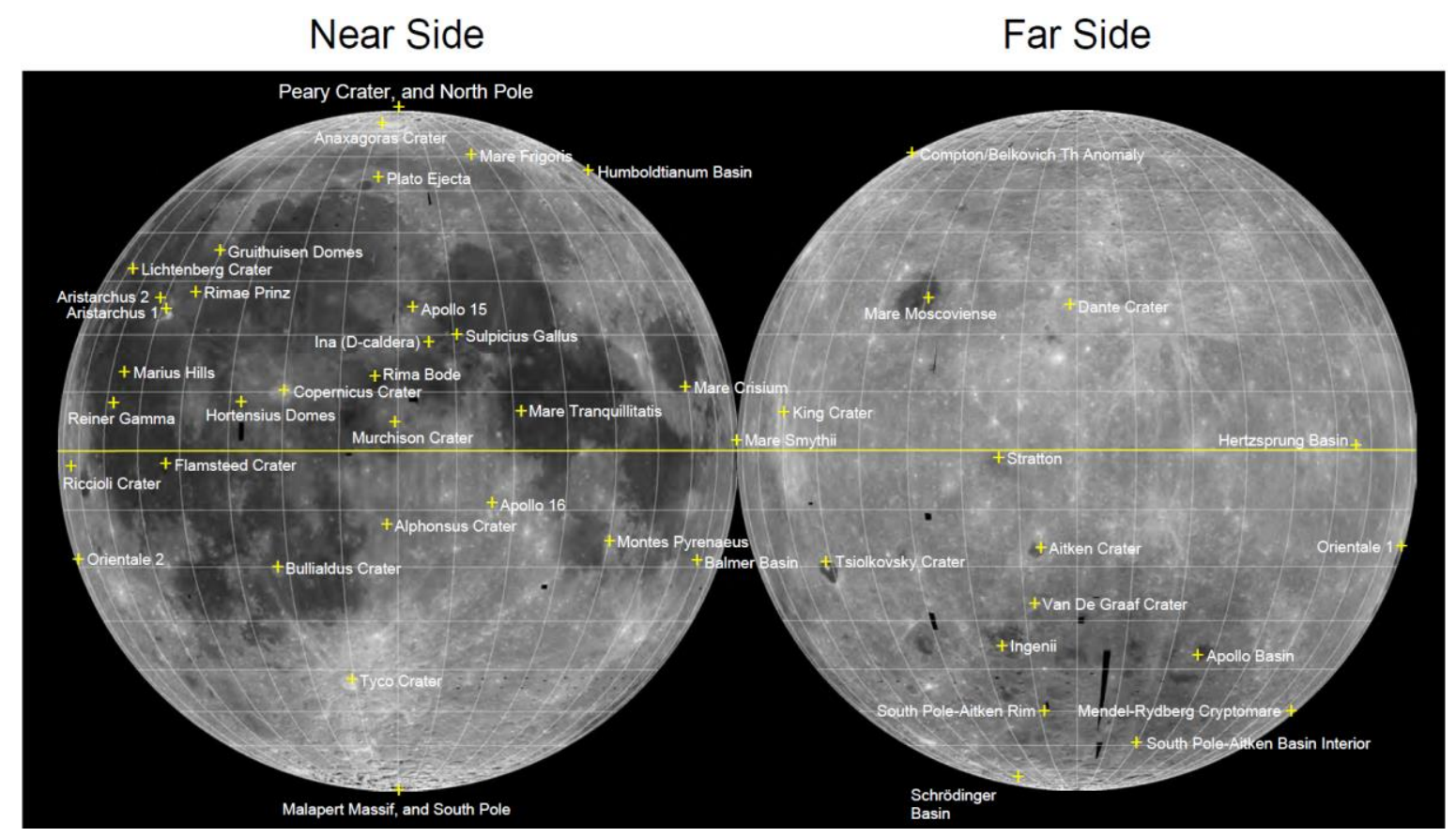

Figure 2. NAS A Cons tellation regions of interest on the Moon, as presentedin Ref. 16

Table 2.Lunar Landing Sites identified by Human Lunar Reference Architecture[18]

\begin{tabular}{|c|c|c|c|c|c|}
\hline & Latitude & Longitude & Site Name & $\begin{array}{c}\text { GPoD Site } \\
\text { Designation }\end{array}$ & Duration \\
\hline \multirow{4}{*}{$\begin{array}{l}\text { Polar } \\
\text { Sites }\end{array}$} & $90^{\circ} \mathrm{N}$ & & North Pole & $\mathrm{E}$ & Sortie \\
\hline & $85^{\circ} \mathrm{S}$ & $13^{\circ} \mathrm{E}$ & Malapert Massif & $\bar{D}$ & Extended Stay \\
\hline & $90^{\circ} \mathrm{S}$ & & South Pole & A & Extended Stay \\
\hline & $90^{\circ} \mathrm{S}$ & & South Pole & $\mathrm{L}$ & Long Duration \\
\hline \multirow{3}{*}{$\begin{array}{c}\text { Mid- } \\
\text { Latitude } \\
\text { Sites }\end{array}$} & $57^{\circ} \mathrm{N}$ & $82^{\circ} \mathrm{E}$ & HumboldtianumBasin & $\mathrm{M}$ & Sortie \\
\hline & $53{ }^{\circ} \mathrm{S}$ & $169^{\circ} \mathrm{W}$ & South Pole-Aitken Basin Interior & $\mathrm{H}$ & Extended Stay \\
\hline & $75^{\circ} \mathrm{S}$ & $132^{\circ} \mathrm{E}$ & Schrödinger Basin & $\mathrm{F}$ & Extended Stay \\
\hline \multirow{6}{*}{$\begin{array}{c}\text { Equatorial } \\
\text { Sites }\end{array}$} & $24^{\circ} \mathrm{N}$ & $47^{\circ} \mathrm{W}$ & Aristarchus Plateau & $\mathrm{K}$ & Extended Stay \\
\hline & $14^{\circ} \mathrm{N}$ & $56^{\circ} \mathrm{W}$ & Marius Hills & $\mathrm{J}$ & Extended Stay \\
\hline & $10^{\circ} \mathrm{N}$ & $20^{\circ} \mathrm{W}$ & Copernicus Crater & $\mathrm{I}$ & Extended Stay \\
\hline & $1^{\circ} \mathrm{N}$ & $88^{\circ} \mathrm{E}$ & Mare Smythii & $\mathrm{G}$ & Sortie \\
\hline & $13^{\circ} \mathrm{S}$ & $3^{\circ} \mathrm{W}$ & Alphonsus Crater & $\mathrm{B}$ & Sortie \\
\hline & $20^{\circ} \mathrm{S}$ & $129^{\circ} \mathrm{E}$ & Tsiolkovsky Crater & $\mathrm{C}$ & Sortie \\
\hline
\end{tabular}

To cover a wide range of potential mis sions at each location, the average power demanded by the customer, $P_{\text {customer, }}$ ranged from $100 \mathrm{~W}$ to $50 \mathrm{~kW}$. The total energy storage requirement, $E_{\text {storage }}$, is then calculated as thenominal power demanded by the customer multiplied by the discharge duration for RFC operations. The full summary of input values being studied is shown in Table 3. Power demand values equal to and less than $1.0 \mathrm{~kW}$ were as sumed to encompass primarily non-human-rated applications, while power demand values in excess of $1.0 \mathrm{~kW}$ were as sumed to apply to potential human-rated applications. A $28-\mathrm{V}$ power bus was selected for use in non-human-rated applications, while the larger human-rated mis sion applications utilized a $120-\mathrm{V}$ power bus. 
Table 3. Input Values usedfor Analysis

\begin{tabular}{|c|c|c|}
\hline $\begin{array}{c}\mathbf{P}_{\text {customer }} \\
k W\end{array}$ & $\begin{array}{c}\mathbf{E}_{\text {storage, }} \\
\text { Lunar Equator } \\
k W \cdot h r\end{array}$ & $\begin{array}{c}\text { Estorage, } \\
\text { Lunar South Pole } \\
k W \cdot h r\end{array}$ \\
\hline 0.1 & 35.6 & 7.3 \\
\hline 0.3 & 107 & 21.9 \\
\hline 0.5 & 178 & 36.5 \\
\hline 1 & 356 & 73.0 \\
\hline 5 & 1780 & 365 \\
\hline 10 & 3560 & 730 \\
\hline 25 & 8900 & 1825 \\
\hline 50 & 17,800 & 3650 \\
\hline
\end{tabular}

The updated PEM fuelcell and electrolyzer RFC modeling tool, discussed in Section III, was used to generate the results for this analysis. When using this tool, no redundancy was considered when accounting for the RFC system hardware mas ses, volumes, and parasitic power. To provide an even comparison, mis sion duration was set at one year with a best case PV availability for the charge/discharge cyclic assessment. For longer operational durations, additional water mass may be required to account for reactant losses. Additionally, no consideration was given towards integrating the RFC system with potential customers, such as propellant scavenging systems or thermal control systems. Such integration has the potential to reduce the RFC systemmass and/or volume extensively, depending on the mis sion architecture. The power demand to the customer was set at a constant level forboth the charging cycle, where power is provided by an external system not included in the RFC systemenvelope, and the discharging cycle. Some mis sions, such as s mall lunar rovers, may require only a smaller subset of the cu stomer power need for discharge operations in order to provide enough power to keep the systems operational in a hibernation mode until solar power and/or heat is again available.

\section{Results}

Having selected the two bounding mis sion locations for the analysis, a series of modeling runs were made based on the as sumptions and inputs discussed in Section V. Figure 3 through Figure 7 present the critical parameters of specific energy, specific power, energy density, and power density as a function of cus tomer power demand and net energy storage required. Due to the different assumptions made between mis sion power demands greater than $1 \mathrm{~kW}$ and less than $1 \mathrm{~kW}$, the data mus tbe analyzed separately for those mis sions.
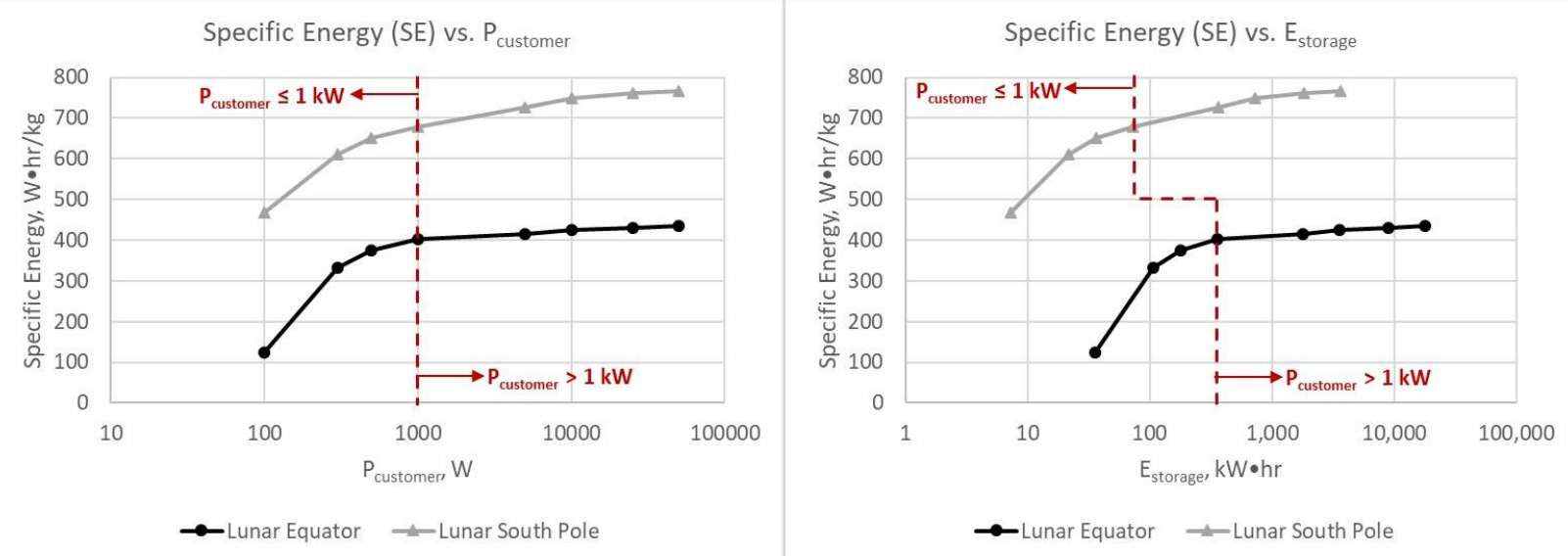

Figure 3. Characterization of the critical parameter Specific Energy relative to power demanded by the cus tomer, $\boldsymbol{P}_{\text {customer }}$ (left), and net energy storage requiredfor the mission, $\boldsymbol{E}_{\text {storage }}$ (right) 

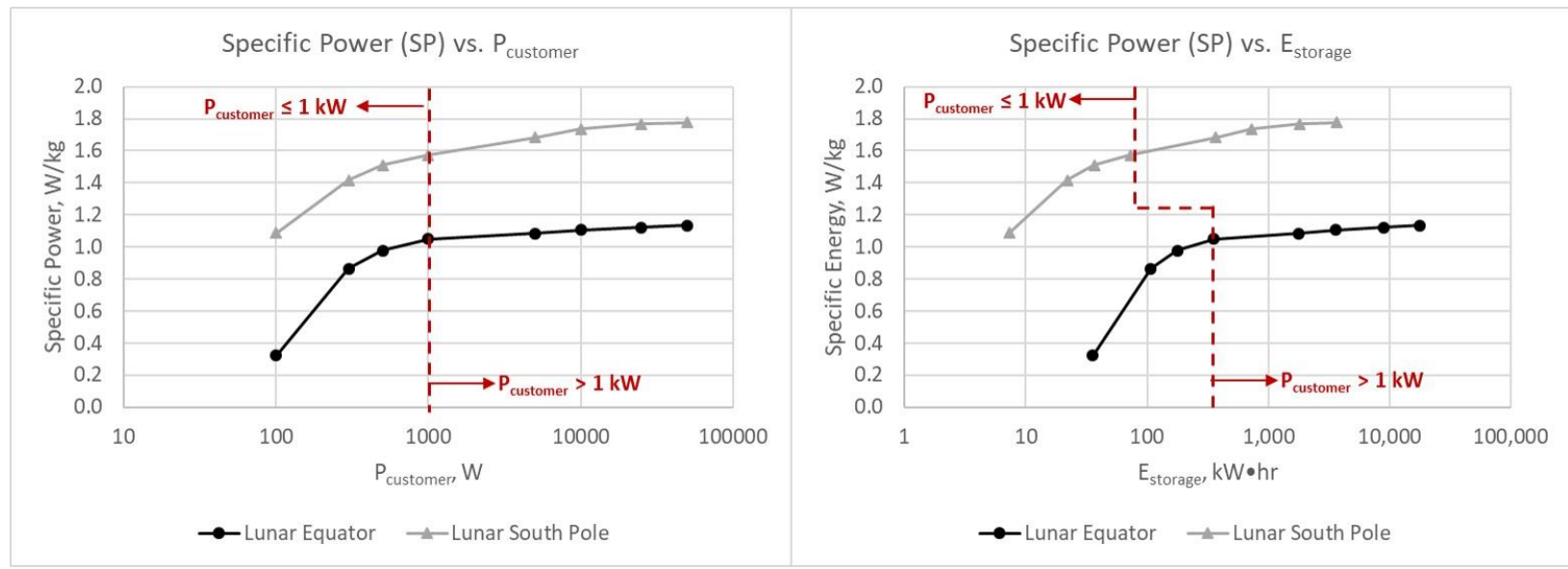

Figure 4. Characterization of the critical parameter Specific Power relative to power demanded by the cus tomer, $\boldsymbol{P}_{\text {customer }}$ (left), and net energy storage required for the mission, $E_{\text {storage }}$ (right)

As shown in Figure 3, the specific energy of an RFC system is greater at the lunar south pole than at the lunar equator by roughly $40 \%$ at most conditions. There is a sharp change in slope when the curve shifts at a customer power demand of $1 \mathrm{~kW}$, which corresponds to the change in as sumptions associated with a small surface application that is not human rated compared to the assumptions made for larger, potentially human rated miss ions. The point at which as sumptions shift is noted by the dashed red line in Figures Figure 3 through Figure 7. As the energy storage and power demand requirements increase, the specific energy increases, with the relative $g$ ain in specific energy leveling off as requirements exceed $1 \mathrm{~kW}$. Notably, this slope is shallower for the lunar equator case than for the les s aggressive lunar south pole case. This is likely due to the lengthy eclipse period that must be survived at the equator, which is longer than that of the south pole. The specific power, characterized in Figure 4, shows a similar trend to specific energy curve, allowing similar conclu sions to be drawn for each of the two parameters.

The trade study runs show that the subsystem hard ware that operates the fuel cell and electrolyzer stacks, also known as the Balance of Plant (BoP), has a larger ratio of total system mass at very low power levels, as shown in Figure 5. This shows that there is a minimum effective power level for RFC energy storage. This power level may change based on the mis sion architecture and requirements. Mis sions with very low power demands should consider all available options prior to selecting an energy storage architecture.

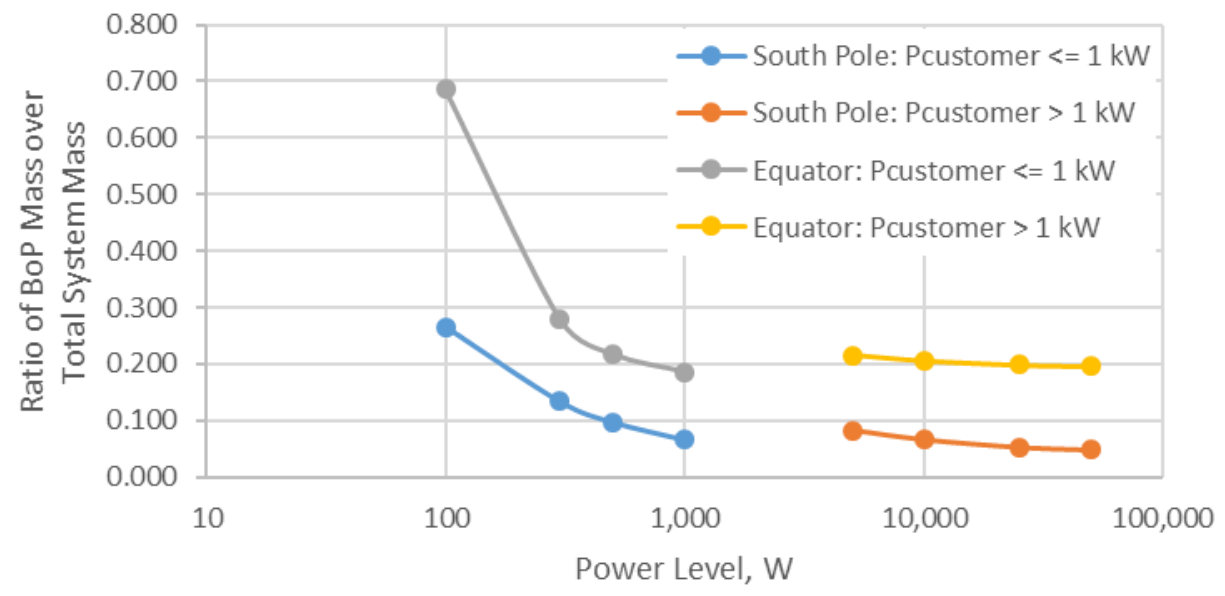

Figure 5.Plot of the ratio of fuel cell and electrolyzer balance of plant mass over the total RFC system mass as a function of customer power demand 

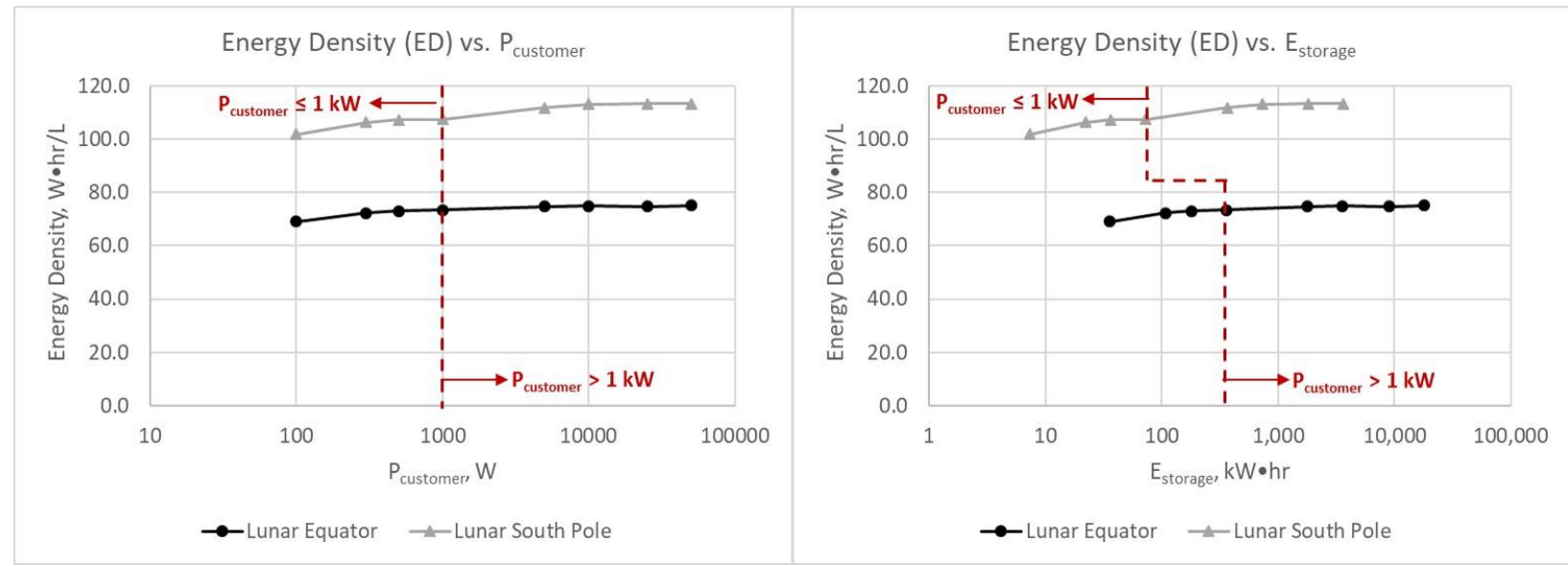

Figure 6. Characterization of the critical parameter Energy Density relative to power demanded by the cus tomer, $P_{\text {customer }}\left(\right.$ left), and net energy storage requiredfor the mission, $E_{\text {storage }}($ right)
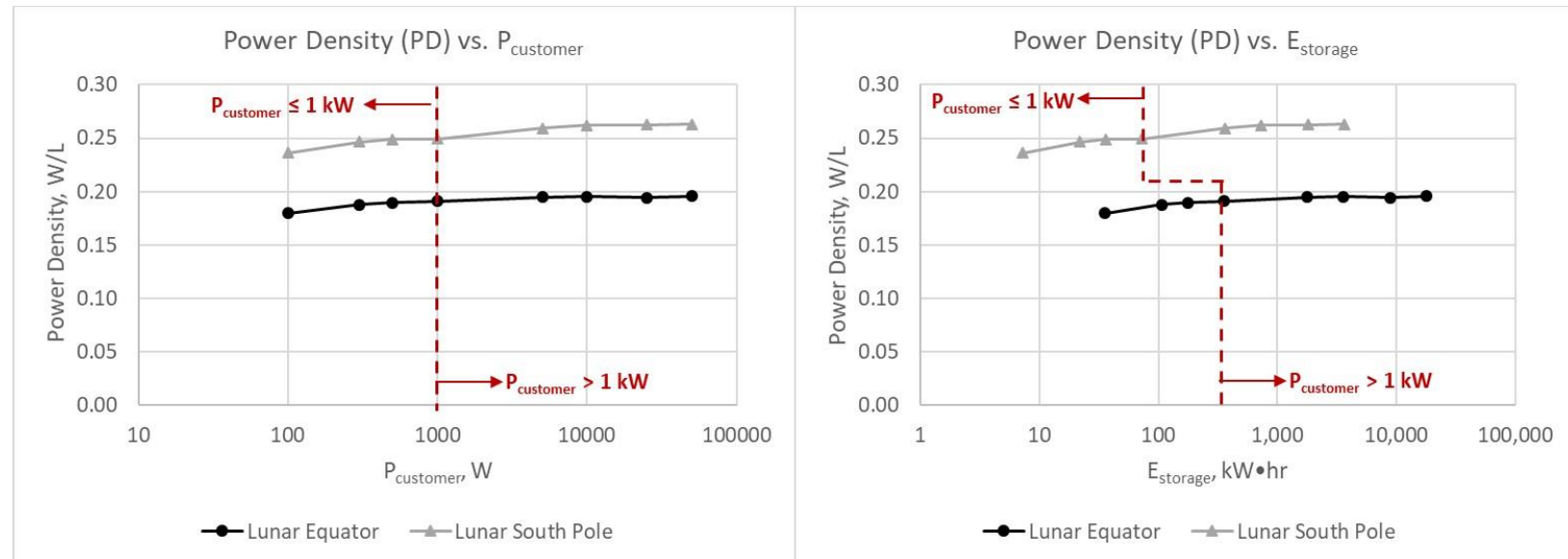

Figure 7. Characterization of the critical parameter Power Density relative to power demanded by the cus tomer, $P_{\text {customer }}$ (left), and net energy s storage requiredfor the mission, $E_{\text {storage }}$ (right)

Figure 6 shows a relatively shallow increase in energy density as the power and energy storage requirements grow, es pecially compared to specific energy. This is also true of power density, depicted in Figure 7. However, there is still a notable difference of approximately $25-30 \%$ in the power and energy densities associated with the lunar equator as compared to the lunar south pole. When defining power and energy density, the volume of the RFC system is determined by the energy storage required for the mis sion. The reactant storage volume is the primary element that dictates the total RFC system volume. For example, an RFC system on the lunar south pole with a customer power demand of $5 \mathrm{~kW}$ would have a reactant storage volume that accounts for as much as $93.5 \%$ of the total system volume, as shown in Figure 8. This percentage is within a range similar to most RFC systems for lunar locations. For systems where power den sity or energy density is of particular concern, the reactant storage volu me could become a primary focus for more detailed study considerations. 


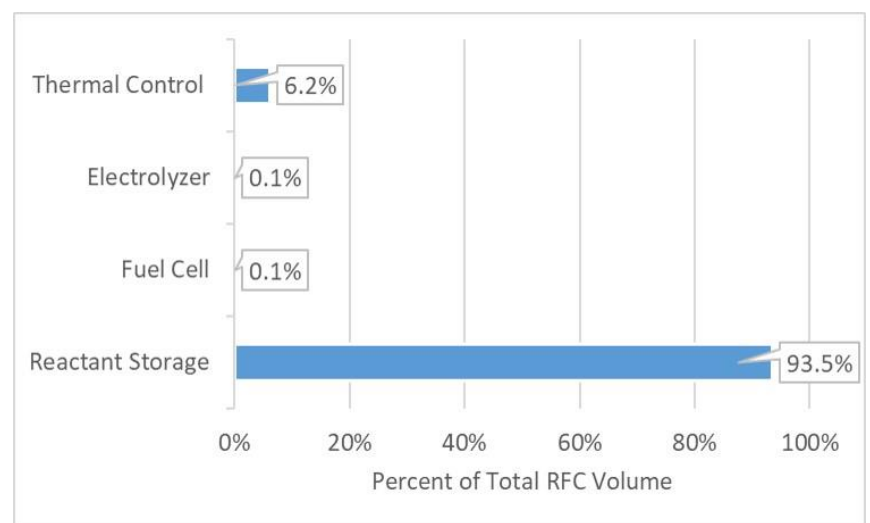

\section{Figure 8. RFC system volume break down for a lunar south pole location with $5 \mathrm{~kW}$ customer power, sorted by its subcomponents: reactant storage, thermal control sys tem, fuel cell sys tem, and electrolyzer system}

By using these charts to generate the critical parameters with a known customer power demand, mission location, and energy storage requirement, a general approximation of the size and scope of an RFC energy storage systemfor a given mission application can be generated. Once an RFC systemis selected as a viable technology solution for a given mis sion, further analysis can be performed to optimize the system and identify further areas of mass and volume savings.

\section{Conclusions}

Both manned and robotic exploration of the lunar surface will require optimized energy storage solutions that minimize system mass and volume. Each mission has a unique set of requirements based on the location and application that may result in different technology solutions. Performing high-level analysis of the available energy storage options may allow mission designers to converge on a technology solution early in the archit ecture definition process, allowing for more effective optimization of the final system design. The data presented in this paper intended to provide boundary values that encompass nearly every lunar surface exploration location and mis sion demand. Using the charts presented, high-level system sizing of an RFC energy storage system for a given lunar mis sion can be performed to aid in architecture trade studies. Following the selection of an RFC system as a viable solution for a given mission, the detailed models used to generate the data in this paper can be used for system optimization and furtherefficiency gains.

\section{Ack nowledgments}

The authors would like to acknowledge the AES program and the AMPS project for funding this opportunity, especially project managers Karin Bozak and Paul Senick. In addition, the authors would like to acknowledge fellow contributors to this work including Luke Gordon, WilliamBennett, James Fincannon, and Jesse deFiebre. Finally, the authors would like to acknowledge the support of the NASA Game Changing Technology program, especially Frederick Elliot and Lee Mason, in coordinating fuel cell development activities at NASA in conjunction with the AMPS team.

\section{References}

[1] Guzik, M.C., et al., "Regenerative Fuel Cell Power Systems for Lunar and Martian Surface Exploration," AIAA SPACE and Astronautics Forum and Exposition, AIAA SPACE Forum (AIAA 2017-5368), Orlando, FL, 2017 doi: 10.2514/6.2017-5368

[2] Barbir, F., Dalton, L., and Molter,T, "Regenerative Fuel Cells for Energy Storage: Efficiency and Weight Trade-Offs," $1^{\text {st }}$ International Energy Conversion Engineering Conference, AIAA/IECEC, (AIAA 2003 -5937), Portsmouth, VA 2003

[3] Rosenberg, D., Pinto, D., Schnitzer, I., "Analysis of Energy Storage System Based on Regenerative Fuel Cells for Spacecraft," $57^{\text {th }}$ International Astronautical Congress, International Astronautical Congress (IAF), Valencia, Spain, 2006, DOI: 10.2514/6.IAC-06-C3.2.03

[4] S. Okaya, A. H. Arastu, J. Breit, "Regenerative Fuel Cell (RFC) for High Power Space System Ap plications", 11TH IECEC/ 2013 Joint Propulsion Conference, San Jose CA

[5] E.R. Joyce, M.P. Snyder, and A.L. Trassare, "Design of a Versatile Regenerative Fuel Cell System for Multi-Kilowatt Applications” AIAA-2010-8710, AIAA SPACE 2010 Conference and Exposition, Anaheim, CA 
[6] D.J. Bents, “Lunar Regenerative Fuel Cell (RFC) Reliability Testing for Assured Mission Success”, T M 2009 -215502, February 2009

[7] Gilligan et al., "Modeling Thermal Control Systems for Extraterrestrial Regenerative Fuel Cells", NASA Thermal and Fluids Analysis Workshop 2017, TFAWS2017-AT-23, TFAWS2017, Huntsville, AL, August 2017.

[8] J.E. Freeh, “Analysis of Stationary, Photovoltaic-Based Surface Power System Designs at the Lunar South Pole”, TM 2009215506, March 2009

[9] Kerslake, T.W., "Electric Power System Technology Options for Lunar Surface Missions,” NASA/T M-2005-213629, 2005

[10] K. M. Somerville , J. C. Lapin, and O.L. Schmidt, "Reference Avionics Architecture for Lunar Surface Systems”, NASA TM 2010-216872, Dec 2010

[11] K.E. Lange, M.S. Anderson, "Lunar Outpost Life Support Architecture Study Based on a High -Mobility Exploration Scenario" AIAA-2010-6237,40th International Conference on Environmental Systems

[12] T. Polsgrove, R. Button, and D. Linne, “Altair Lunar Lander Consumables Management” AIAA 2009-6589, AIAA SPACE 2009 Conference and Exposition, Pasadena, CA

[13] Petri, D.A., Cataldo, R.L., and Bozek, J.M., "Power System Requirements and Definition For Lunar and Mars Outposts - A Review of the Space Exploration Initiative's NASA 90 Day Study," $4^{\text {th }}$ International Energy Conversion Engineering Conference, AIAA/IECEC, (AIAA 2006-4103), San Diego, CA 2006, DOI: 10.2514/6.2006-4103

[14] Ogden, D.H., "Study of a Water Electrolysis system for a Lunar Base Power Station", Quarterly Report HGS-R102-69 under contract NAS8-21190

[15] “Energy Storage Technologies for Future Planetary Science Missions”, NASA Planetary Science Division, December 2017, JPL D-101146

[16] Gruener, J.E., and Joosten, B.K., "NASA Constellation Program Office Regions of Interest on the Moon: A Representative Basis for Scientific Exploration, Resource Potential, and Mission Operations", Lunar Reconnaissance Orbiter Science Targeting Meeting, \#6036, Tempe, AZ, 2009

[17] "NASA's Exploration System Architecture Study", NASA TM-2005-214062, November 2005

[18] Seaman, C.H., "Goals and Strategies for the Human Lunar Reference Architecture", 10th International Symposium on Artificial Intelligence, Robotics and Aut omation in Space; 26-31 Aug. 2010; Hokkaido; Japan, JSC-CN-21470 